Published in final edited form as:

Top Stroke Rehabil. 2007 ; 14(2): 13-20.

\title{
Two Sides to the Caregiving Story
}

\author{
Linda. L. Pierce, PhD, RN, CNS, CRRN, FAHA, \\ Professor, The University of Toledo College of Nursing, Toledo, Ohio \\ Victoria Steiner, PhD, \\ Assistant Professor, The University of Toledo College of Medicine, Toledo, Ohio
}

Amy Govoni, MSN, RN, CS, Associate Professor, Cleveland State University School of Nursing, Cleveland, Ohio

Teresa Cervantez Thompson, PhD, RN, CRRN-A, and

Dean and Professor, Madonna University College of Nursing and Health, Livonia, Michigan

Marie-Luise Friedemann, PhD, RN

Professor, Florida International University School of Nursing, Miami, Florida

\begin{abstract}
Purpose-This descriptive study examined problems and successes that a sample of 73 adult caregivers new to the role expressed in the first year of caring for stroke survivors. Data were collected from May 2002 to December 2005.

Method-Bimonthly, trained telephone interviewers asked the participants open-ended questions to elicit their experience in caregiving. Guided by Friedemann's framework of systemic organization, we analyzed the data using Colaizzi's method of content analysis.

Results-There were 2,455 problems and 2,687 successes reported. Three themes emerged from the problems: being frustrated in day-to-day situations (system maintenance in Friedemann's terms), feeling inadequate and turning to others for help (coherence), and struggling and looking for "normal" in caring (system maintenance vs. change). Three themes were attributed to the successes: making it through and striving for independence (system maintenance), doing things together and seeing accomplishments in the other (coherence), and reaching a new sense of normal and finding balance in life (individuation and system maintenance).
\end{abstract}

Conclusion-These findings provided an in-depth, theory-based description of the experience of being a new caregiver and can help explain how caring can be a difficult yet rewarding experience. Knowledge of the changes over time allows health care professionals to tailor their interventions, understanding, and support.

\section{Keywords}

caregivers; caring; problems; stroke; successes

Stroke is a medical emergency and on average, it occurs every 45 seconds. There are over 5 million people in America, who on have survived a stroke and who live with its aftereffects. 1 Most of these individuals return home after initial poststroke treatment and are cared for by informal caregivers, such as family members, neighbors, and friends.2 Unlike chronic conditions in which caregivers have time to master the role, caregivers of stroke survivors must quickly learn how to care for these persons.3,4 


\section{Background and Purpose}

Stroke can result in cognitive, emotional, social, behavioral, and functional impairments. 1 The profound changes that can accompany stroke may create considerable uncertainty in caring for the affected person and may necessitate changes in lifestyle or behavior patterns of both caregivers and stroke survivors.5-8 Research suggests that stroke is a family affair,7 and there needs to be more rigorous attention to caregivers' issues and concerns. Caregivers need to learn their role.9 Professionals need to think about, work with, and involve caregivers during recovery from stroke. 8,10

\section{Problems}

Accounts of high levels of distress in caregivers of stroke survivors have been reported in the literature.10-13 Early studies in the 1990s indicated that significant stress and depression were experienced by caregivers involved in a caring relationship for another, 14,15 and this continues into the 21 st century. 12 For example, in a study by Levine and colleagues, 16 caregivers $(n=$ 95) felt burdened or constantly overwhelmed every day with continuing problems, such as not having enough time for themselves. Of these caregivers, between one half to one third expressed feelings of anxiety and depression. 16 The care recipient's state of psychological well-being may affect the caregiver, which, in turn, affects the care recipient.17 A more recent study of stroke spousal caregivers revealed that this group experienced a decreased level of psychological well-being.18 Boter and Rinkel6 found that stroke survivors were most concerned with physical and emotional problems, whereas caregivers were more focused on psychosocial problems. In the first months of dealing with stroke, caregivers were thinking of long-term problems, particularly social support. 8 Caregivers with more social support had fewer depressive symptoms and greater well-being and general health that was independent of social problem-solving skills.19

O'Connell and Baker20 noted that caregivers experienced considerable uncertainty about their role in caring for stroke survivors. In qualitative pilot work prior to this current study, Pierce et al.4 reported problem themes learned from the caregivers $(n=9)$ themselves. In the first 3 months of caring, caregivers reported problems that impacted them and their care recipients: having independence issues, dealing with emotions, living with physical limitations, managing comorbid conditions, participating in physical therapy, and having sleeping difficulties. The only problem that focused solely on the caregivers, balancing it all, was related to role strain. 4 In a larger study by King and Semik, 10 the most difficult time for caregivers $(n=93)$ was hospitalization of the care recipient for the initial stroke. However, difficulties continued in the first months post discharge into the second year of caring. A combination of factors caused these difficult times: uncertainty with the situation and lack of confidence, information, and skills; new and increased responsibilities; and the challenge of handling the survivor's impairments and emotions. Later in the stroke trajectory, a plateau in the survivor's function, health problems of caregiver and survivor, financial difficulties, and caregiver's increased emotional distress were more prominent. Unmet needs were reported by over half of these caregivers; the caregivers felt unprepared for caregiving, were unable to enhance the survivor's emotional and physical function, and had difficulty sustaining self as well as family.10 Similarly, in a study by Bakas and colleagues, 5 major areas of concern included lack of information about stroke, including emotions and behaviors to be expected post stroke; physical and instrumental care; and impact of role on the caregiver's personal life.

\section{Successes}

Upon reviewing the literature on the effects of caregiving as it affects caregivers, it may be tempting to conceptualize caregiving as a purely negative problem-oriented process that produces feelings of distress and burden. However, there is evidence in the literature of feelings 
of well-being and positive effects of caring on the caregivers. In fact, these positive outcomes are likely to be the motivations to continue the caring relationship. 21

Even though not much has been published, the early study of Farran and associates 21 serves as an exemplar in that it points to the need for understanding the meaning of caring for another and the potentially positive outcomes for the caring person. In that study, 94 caregivers valued their feeling of confidence as being a factor that motivated them to give good care. The study also addressed interpersonal issues. Caregivers valued positive aspects of relationships and of the caring situation in a family context. For example, positive family and social relationships, the care recipient's love for the caregiver, pleasant memories of others, and accomplishments were valued by the family caregivers. 21

Evans, Bishop, and Ousley22 in interviewing family caregivers of stroke survivors found that family relations seemed to be a source of strength. The maintenance of reciprocity in a relationship seems to play a major role in caregiver satisfaction. In a study with predominately white caregivers of stroke survivors $(n=9)$, Pierce and colleagues 23 found that caregivers pulled together with family and friends, felt connected, and supported one another. One caregiver shared, "We have become a closer knit family, each helping one another, together, getting each others' ideas and thoughts as we care for our mother." Pierce24 in 2001 reported similar findings with 24 African American caregivers of stroke survivors. These families worked closely together in caring, and these relationships provided satisfaction. 24 This current research answers the secondary aim of a National Institutes of Health study by providing an in-depth, theory-based description of the experience of caring, that is, problems and successes adult caregivers new to the role expressed in the first year of caring for stroke survivors.

\section{Method}

\section{Sample and setting}

For this study, we recruited caregivers from rehabilitation facilities in northern Ohio and southern Michigan from May 2002 through December 2004 and followed them for 1 year. Other inclusion criteria were that the care recipient had a new diagnosis of stroke and was discharged to home following treatment. The caregiver was the primary person responsible for providing the day-to-day care and was able to read, write, and understand English. This study was guided by Friedemann's25,26 framework of systemic organization.

\section{Framework of systemic organization}

According to Friedemann,25,26 behavior patterns to strive toward congruence or balance that are acted out in daily life can be observed and organized into four process dimensions: system maintenance, coherence, individuation, and system change. System maintenance in caregiving situations involves the tasks of caring for the stroke survivor and the organization of tasks, time schedules, work assignments, communication patterns, and procurement of outside help.

Maintenance also includes those actions caregivers undertake to maintain their own well-being, such as rest and sleep, social contacts, good nutrition, and recreation. Coherence signifies being at peace with oneself or feeling as one unified self. Coherence can be achieved by caregivers through a variety of actions leading to renewed energy and a positive attitude. These actions prevent anxiety, depression, exhaustion, or feelings of inadequacy. The third process dimension is individuation, a process of self-development through learning, experiencing, and finding a purpose in one's situation and life in general. Caregivers learn by giving care, exploring facts about stroke, interacting with others, or finding value in their caring through religion or spirituality. Individuation leads to system change as caregivers become conscious of the impact of their new responsibilities and make changes in their priorities, attitudes, and values and, as a result, assume new behavior patterns.25,26 


\section{Data collection and analyses}

Demographic baseline data, such as age, gender, and employment, were obtained. Descriptive statistics were computed to describe the sample. Caregivers were queried every 2 weeks via a telephone by trained interviewers. The biweekly telephone contact prompted recall of events, and contact was made $98 \%$ of the time. With open-ended questions, participants' caregiving experiences were elicited. The interviewers asked what was not working well ("What was the biggest challenge" and "What were other problems") and what was going very well ("What was the most successful thing that has happened" and "Did you have any other successes") for the caregiver and the care recipient in the caregiving situation. These data were immediately entered into web-based forms by the interviewers. The narrative data were later cleaned and entered as text files into QSR N 5,27 a qualitative software management program, and analyzed using Colaizzi's 28 rigorous method of content analysis.

In this content analysis, all investigators independently read all verbatim transcripts of the data to establish a baseline impression of the whole dialogue. They then reread the transcripts and extracted significant statements relating to the experience of caring. Significant statements and phrases pertaining directly to the experience of caring were replete throughout these data and early signs of clustering were evident. Using a coding categorization, based on Friedemann's25,26 framework of systemic organization that was previously developed, piloted, and confirmed,9,23 statements and phrases were coded by the investigators as a group. Throughout this process, the investigators discussed differences in coding or categorizing the data until final agreement was reached. Analysis of these coded data revealed emergent themes. Finally the results were integrated into an exhaustive description of the phenomena. With more than 5,000 entries, these data are saturated and expand the knowledge of the experience of caring in home settings.

Trustworthiness of the data and interpretations were further enhanced in the following ways. The interviewers were trained in the use of the instrument, read literature, and attended presentations by the investigators and the theorist. The biweekly interviews provided a vast amount of data from the caregivers and the interviewers, which added to the trustworthiness of the overall findings. Finally, although the researcher is part and parcel of the qualitative research process, the added dimension of having all investigators/authors involved for content clarification, refinement, and concurrence enhanced the data interpretation.

\section{Results}

\section{Profile of caregivers and care recipients}

Seventy-three caregivers completed the study: $18(25 \%)$ men and 55 (75\%) women. Of these, there were $34(47 \%)$ wives, 16 (22\%) husbands, $13(18 \%)$ daughters, $1(1 \%)$ son, and $9(12 \%)$ other relatives or friends. Sixty-two (85\%) caregivers were white, $9(12 \%)$ were African American, $1(1 \%)$ was Hispanic, and $1(1 \%)$ was American Indian. The caregivers' average age was 55 years, and the average years of education were 13. Twenty-seven (37\%) caregivers worked full-time, $12(16 \%)$ worked part-time, and 34 (47\%) did not work. Among the stroke survivors, $58 \%$ were men and $85 \%$ were white. Their mean age was 63 years (range, 32-88 years).

\section{Findings}

Caregivers reported a total of 2,455 problems and 2,687 successes during the interviews for the first year of caring. Although qualitative analyses do not allow for statistical comparisons, the themes within the experience of caring are distinguished and described. 
Problems-The mean number of problems reported by each caregiver over the year was 34 , with a range of $0-15$ problems reported in each 2 -week period. Three major themes emerged from these data. The first theme of being frustrated in day-to-day situations, system maintenance in Friedemann's terms,25,26 centered on physical tasks and household chores, as well as role reversal and emotional and behavioral issues. For example, one wife said, "There was not enough time in the day to provide care....Taking care of him: bathing and dressing." One husband shared, "I had to learn how to cook, clean, pay bills, etc... as wife has always taken care of household maintenance." Another wife noted her changed role and shared, "It's almost like having another child because I have to remind him of things a lot. It's not like it used to be. Our relationship is different, it's not the same." Getting stroke survivors to listen, accept, and do what they were able to accomplish was a challenge for caregivers. A daughter shared, "The day to day challenges to get him to accept that things will never be the same is difficult." A husband said, "Changes must be made in our living arrangements and getting her to accept this is a challenge. Everyday is different." Another caregiver summed up many responses, when she said, "Some days he is a pussy cat and other days, a grizzly bear."

The second theme was feeling inadequate and turning to others for help, defined as coherence according to Friedemann.25,26 Caregivers became overwhelmed and reached out for support. A woman's comment is representative: "This will be a lifelong struggle with my husband.... It's like this baggage that every morning you have to pick up and take with you. Even at night it doesn't completely go away, because he may wake up and can't swallow." And so they sought help from family and others. Some caregivers were disappointed with the amount of assistance provided, but most caregivers said over and over that family and friends are very loyal and they continue to be supportive and helpful. A son said, “...I can call [family and friends] anytime."

The final theme, struggling and looking for "normal" in caring, system maintenance versus change according to Friedemann, 25,26 involved how, or if, life was moving to some definition of normal (routine or usual) for the caregivers. A husband said, "The whole thing [stroke] is the biggest challenge. You never think that you will be in this position and when you are, you haven't got a clue [how to deal with it]." One wife gave the following account, "Sometimes you feel like you want a truck to hit you, but you don't want to leave someone else with the mess." Another wife shared, "Life is never going to be normal again, but it is good. I never thought he would be doing the things that he is doing now. You truly learn to value every day."

Over time, caregivers reported frustrations with day-to-day situations that they worked on alone or with the care recipient. More problems were revealed in the first 3 months, and the caregivers' responses revealed a pattern of transition that resembled the findings of King and Semik.10 Initially, caregivers' problems centered on physical tasks in caregiving and then shifted to dealing with behavioral and interpersonal issues of the stroke survivor, exposing their feelings of being overwhelmed and reaching out for support. By month 12, caregivers saw some normality to their life or redefined what normal now was for them.

Successes-The mean number of successes reported by each caregiver over the year was 37 , with a range of $0-10$ successes reported in each 2-week period. The first theme that was attributed to these data was making it through and striving for independence, system maintenance in Friedemann's terms.25,26 The stroke survivor became more independent with the help and encouragement of the caregiver. One wife said that she tries to urge her husband on in making gains toward recovery and that she "heard him singing in his room the other day and that tickled her because his speech isn't always so good, but he was singing." Another caregiver shared that motivation is part of caring, "We do everything that we did before, maybe not as fast or graceful." 
The second theme of doing things together and seeing accomplishments in the care recipient emerged, coherence or togetherness in Friedemann's words.25,26 One wife said, "I sit there and tell him that he looks handsome. He laughs and tells me that he's just an old man. To me, he looks like his 'old self' and it just feels good." A daughter noted that they were able to return to doing things as a family when her father was more independent in walking: "We went to the The Ohio State [university football] game with some family. It was so exuberating. They were close, you could touch the cheerleaders, the band was right there. He had life in his face. It was a neat experience seeing him enjoy it."

The third and final theme was reaching a new sense of normal and finding balance in life, individuation and system maintenance according to Friedemann.25,26 A wife commented, "My husband is much more positive now. I believe that when things happen in life, it either makes you a better person or a worse person and I think that he has become more appreciative of what he has in life and dropped some of the bull— along the way."

Successes reported at 3,6, and 9 months and at the end of the study revealed a pattern of beginning system change over time.25,26 Caregivers' successes were seen initially in terms of the care recipients' progress to regain what they had lost. Thus, caregivers' success focused on the "other." This expanded over time to caregivers' descriptions of their own and the care recipients' involvement in activities and enjoyment of life, such as going out to dinner (coherence).25,26 Successes were described in terms of life becoming organized and routine (system maintenance); toward the end of the study, caregivers described being able to leave the care recipient, socialize, resume prior activities, and enjoy interactive opportunities.25,26

\section{Discussion}

There are truly two sides to the caregiving story. Although the situation may be the same, these caregivers experienced both positive (successes) and negative (problems) aspects as a result. Consequently, the themes for the problems and successes are also similar. For example, looking for normal was seen as a problem in that caregivers wished things were as they once were; however, over time, they were able to find a new sense of normal and come to a fresh balance in their lives and appreciation for what they had. In fact, these caregivers expressed more successes during the first year of caring than problems.

At 3 months, the caregivers were dealing with problems that resulted in basic system maintenance. Similar to King and Semik,10 they were very focused on the care recipients' function and tasks needed to compensate for the loss of abilities. In general, the caregivers described problem solving in terms of what the care recipient was doing or needing. Caregivers were also working on initial system changes in trying to find the time and means to manage the impact of the stroke. They expressed worries related to being overwhelmed, not having enough time for self, and being concerned about the care recipient's progress and safety. At 6 months, the problem emphasis had moved from tasks to behavioral issues as caregivers tried to adjust to the daily hassles of living and dealing with stroke. The moods, fears, and worries shared showed that the reality of the situation had "hit home" as caregiver and care recipient now struggled together. The caregivers were working toward adjusting their lives, dealing with uncertainty and adapting to changes as O'Connell and Baker20 also reported, and dealing with the issues of individuation, as they learned and grew from the experience and faced the reality of caring over time. Caregivers continued to describe their worries and concerns related to having time to care for self, sharing frustrations, and being overwhelmed, as they dealt with the care recipients' progress or lack thereof and their moods, memory issues, and depression. At 9 months, the caregivers shared care recipients' behaviors that were frustrating and additional concerns about personal safety or unsafe actions. By 12 months, the caregivers described a normalization of their lives, incorporating whatever residual needs still existed for 
the care recipient. This may reflect an acceptance of the situation or an achievement of successes, such as learning the role of caregiver.9 Caregivers were in a process of dealing with letting go of trying to control the situation, as they struggled with the care recipient in daily life events. The struggles reflected system maintenance and realistic movement toward coherence and change within the family system.

At 3 months, successes dealt with the care recipients' improved function of walking, physical balance, and ability to do things or therapy going well. At 6 months, even though the emphasis remained on the care recipient, there were reports of success in "getting out and doing things together." At 9 months, there was continued focus on being able to return to society. This was coupled with increased reports of the care recipient being able to do things for themselves. These findings of recognizing the care recipient's strengths support earlier work by Ferran and associates 21 who found that there was a focus on relationships and being together. At 12 months, acceptance and working things out were reported successes. More examples of getting out into the community and having more social successes were shared at this point. Positive outcomes seemed to strengthen relationships.24,29 These successes support the movement toward working on their relationships and demonstrating individuation and coherence. 25,26 True system change was not yet achieved as caregivers still tried to maintain what they had. Representative is the comment that one caregiver shared, "Stroke and the (caring) situation have changed my outlook on life.... I can let the small things go, because they can wait."

In summary, initially the caregivers were concerned with the challenges of new tasks and learning new roles, and they just tried to make it through the day (system maintenance and individuation). 25,26 Successes were seen in terms of the care recipient doing a task or needing less assistance with that task. From that early stage, problems as well as successes reflected managing and creating routines or the care recipient completing therapy treatment. With time, individuation began as caregivers became confident in leaving care recipients alone and as care recipients were able to do some things on their own. A rebuilding of the relationship between caregivers and care recipients also began, as they moved toward coherence. Together they went out, participated in familiar or new activities, and began to see a future.25,26

It is up to the reader to decide if these findings apply to their locales and populations of caregivers. Further research is needed with more diverse locations and cultural groups, as well as with caregivers of individuals with other chronic diseases. Qualitative outcome analysis 30 might be useful for building on this study to extend the focus from understanding the experience of caring and the problems and successes of caregivers of stroke survivors to confirming the applicability of clinical strategies.

\section{Implications for Health Care Providers}

Findings of this study indicate crucial issues related to both sides of the caregiving story, problems and successes. The opportunity to explore phenomena related to rehabilitation and how various phenomena are related provides a basis for understanding practice. Research findings can be applied in ways that enhance practice and ultimately improve outcomes. Friedemann's25,26 framework allowed us to not only identify specific problems and successes but to also understand their interactions within the family system. This provides information on when and where to intervene with caregivers and on the implications of such interventions. Assessing caregivers' distress and helping them manage their problems, along with identifying and building on their successes, are critical to long-term adaptation. As there is a foreseeable progression over time, providers should be able to assess where the caregivers are in this adjustment process. They can then support caregivers to reach the next step.

Health care providers must think of caregivers as people who need care and should teach them strategies that they can use to manage frustrations with the physical tasks, such as bathing, 
dressing, and grooming. Arranging for in-home or outpatient physical, occupational, or speech therapy and in-home peer assistance are ways that caregivers can learn the day-to-day skills of physical caring. Being connected to therapists, peers, family, friends, and/or neighbors who have worked with others or experienced similar situations may help caregivers avoid feelings of frustration and inadequacy with caring. In-person or online support groups may also provide welcome relief; caregivers can share problematic issues, learn decision-making tactics, and develop problem-solving skills, so that they feel less alone in this caregiver journey. Professional counseling for the caregiver and/or family is another strategy that may be beneficial in helping them deal with behavioral and interpersonal issues as they strive for life to be "normal" again.

It is paramount to provide encouragement for the caregivers to support the stroke survivor in achieving a level of independence. The findings of this study indicate that it is important for caregivers and stroke survivors to do things together as time passes. Caregivers need to celebrate small and large successes in the stroke survivor's recovery of independence. If this is not possible, they need support and encouragement to deal with what is reality or to develop a new sense of "normal."

\section{Conclusion}

As initial hospitalization stays continue to shrink, it is imperative for health care professionals to intervene with new stroke survivors and their caregivers. For example, rehabilitation team members should teach caregivers the physical tasks of providing care and later should provide emotional support. Too often caregivers are ignored, and yet they are key players in successful home caring in that first year. Home care provided by informal caregivers may decrease the nearly 14 billion dollars per year of direct costs for nursing home care for stroke survivors. 1 This study provided an in-depth, theory-based description of the experience of caring. The resultant findings help clarify how caring for stroke survivors can be a difficult, yet rewarding experience. Knowledge of the expected trajectory allows health care professionals to tailor their interventions, understanding, and support.

\section{Acknowledgements}

This study was supported through a National Institute of Nursing Research, National Institutes of Health grant number RO1 NR007650. All caregivers are thanked for their participation. The recruiters and interviewers are recognized for their work. The contributions of Barbara Hicks, MSN, RN, CNS, Associate Professor Emerita and Study Coordinator; Jamie Vargas, BS, Software Engineer; and Marc Miller, BS, Computer Support Specialist at The University of Toledo are gratefully acknowledged.

\section{References}

1. American Stroke Association [ASA]. Stroke facts 2006: all Americans. 2006. Available at: www.americanheart.org

2. Kalra L, Evans A, Perez I, Melbourn A, Patel A, Knapp M, Donaldson N. Training carers of stroke patients: randomized control trial. Br Med J 2004;328:1-5. [PubMed: 14703521]

3. Brereton L, Nolan M. "Seeking": a key activity for new family carers of stroke survivors. J Clin Nurs 2002;11:22-32. [PubMed: 11845752]

4. Pierce L, Steiner V, Hicks B, Holzaepfel A. Perceived problems of new caregivers of persons with stroke. Rehabil Nurs 2006;31(4):166-172. [PubMed: 16789675]

5. Bakas T, Austin J, Okonwo K, Lewis R, Chadwick L. Needs, concerns, strategies, and advice of stroke caregivers the first six months after discharge. J Neurosci Nurs 2002;34:242-252. [PubMed: 12391740]

6. Boter H, Rinkel G. Outreach nurse support, after stroke: a descriptive study on patients and carers needs, and applied nursing interventions. Clin Rehabil 2002;18:156-163. [PubMed: 15053124] 
7. Burman M. Family caregiver expectations and management of stroke trajectory. Rehabil Nurs 2001;26:94-100. [PubMed: 12035695]

8. Garrett D, Cowdell F. Information needs of patients and carers following stroke. Nurs Older People 2005;17:14-17. [PubMed: 16161322]

9. Thompson, T.; Pierce, L.; Steiner, V.; Govoni, A.; Hicks, B.; Friedemann, M-L. What happened to normal? Learning the role of caregiver. Online J Nurs Informatics [serial online]. 2004. Available at: http://www.eaa-knowledge.com/ojni/ni/8_2/caregiver.htm

10. King R, Semik P. Stroke caregiving: difficult times, resource use, and needs during the first 2 years. J Gerontol Nurs 2006;32(4):37-44. [PubMed: 16615711]

11. Anderson C, Linto J, Stewart-Wynne E. A population-based assessment of the impact and burden of caregiving for long-term stroke survivors. Stroke 1995;26:843-849. [PubMed: 7740578]

12. Clark P, King K. Comparison of family caregivers: stroke survivors versus persons with Alzheimer's disease. J Gerontol Nurs 2003;29(2):45-53. [PubMed: 12640864]

13. King R, Carlson C, Shade-Zeldow Y, Bares K, Roth E, Heinemann A. Transition to home care after stroke: depression, physical health, and adaptive processes in support persons. Res Nurs Health 2001;24:307-323. [PubMed: 11746061]

14. Carlson R, Keller M. Control over daily life and caregiver burden: little things do count. Rehabil Nurs Res 1992;1(1):6-13.

15. McLean J, Roper-Hall A, Mayer P, Main A. Service needs of stroke survivors and their informal carers: a pilot study. J Adv Nurs 1991;16:559-564. [PubMed: 1856375]

16. Levine C, Albert S, Hokenstad A, Halper D, Hart A, Gould D. This case is closed: family caregivers and the termination of home health care services for stroke patients. Milbank Q 2006;84(2):305-331. [PubMed: 16771820]

17. Burgener S, Chiverton P. Conceptualizing psychological well-being in cognitively-impaired older persons. Image J Nurs Sch 1992;24(3):209-213. [PubMed: 1521849]

18. Forsberg-Warleby G, Moller A, Bloomstrand C. Spouses of first-ever stroke patients. Stroke 2001;32:1646-1651. [PubMed: 11441214]

19. Grant J, Glandon G, Elliot T, Giger J, Weaver M. Caregiving problems and feelings experienced by family caregivers of stroke survivors the first month after discharge. Int J Rehabil Res 2004;27:105111. [PubMed: 15167107]

20. O'Connell B, Baker L. Managing as carers of stroke survivors: strategies from the field. Int J Nurs Pract 2004;10:121-126. [PubMed: 15149459]

21. Farran C, Keane-Hagerty E, Salloway S, Kupferer S, Wilken C. Finding meaning: an alternative paradigm for Alzheimer's disease family caregivers. Gerontologist 1991;31(4):483-489. [PubMed: 1894152]

22. Evans R, Bishop D, Ousley R. Providing care to persons with physical disability: effect on family caregivers. Am J Phys Med Rehabil 1992;71(3):140-144. [PubMed: 1385711]

23. Pierce L, Steiner V, Govoni A, Hicks B, Thompson T, Friedemann M. Caregivers pull together and feel connected in caring for persons with stroke. Neurosci Nurs 2003;36(1):32-39.

24. Pierce L. Coherence in the urban family caregiver role with African American stroke survivors. Top Stroke Rehabil 2001;8(3):64-72. [PubMed: 14523739]

25. Friedemann, M-L. The Framework of Systemic Organization: A Conceptual Approach to Practice and Research with Families and Family Members. Thousand Oaks, CA: Sage; 1995.

26. Friedemann, M-L. The framework of systemic organization. 2006. Available at: http://www.angelfire.com/ak3/Friedemann/Framework11.htm

27. Richards, L. N 5 Reference Guide. Australia: QSR International Pty Ltd; 2000.

28. Colaizzi, P. Psychological research as the phenomenologist views it. In: Valle, R.; King, M., editors. Existential Phenomenological Alternatives for Psychology. New York: Oxford University Press; 1978.

29. Pierce L, Steiner V, Govoni A, Hicks B, Thompson T, Friedemann M. Internet-based support for rural caregivers of persons with stroke shows promise. Rehabil Nurs 2004;29(3):95-99. 103.

[PubMed: 15152419] 
30. Morse J, Penrod J, Hupcey J. Qualitative outcome analysis: evaluating nursing interventions for complex clinical phenomena. Image J Nurs Sch 2000;32(2):125-130. 